\title{
THE KEY ROLE OF HUMAN MICROBIOTA IN BREAST CANCER
}

\begin{abstract}
Alessio Filippone ${ }^{1}$, Cristina Rossi ${ }^{1}$, Maria Maddalena Rossi ${ }^{1}$, Donatella Guarino ${ }^{1}$, Claudia Maggiore $^{1}$, Annalisa Di Micco ${ }^{1}$, Laura Ticca ${ }^{2}$, Sara Di Palma ${ }^{3}$, Rolando Alessio Bolognino ${ }^{4}$, Alejandro Martìn Sànchez ${ }^{1}$, Gianluca Franceschini ${ }^{5,6}$ Riccardo Masetti $^{5,6}$ and Stefano Magno ${ }^{1}$

1. Center for Integrative Oncology, Breast Cancer Center. Fondazione Policlinico Universitario Agostino Gemelli, IRCCS, 00168 Rome, Italy

2. Cellular and molecular biologist, Freelance Researcher. Rome, Italy

3. DD Clinic Reseach Institute Foundation, 81100 Caserta, Italy

4. Università degli Studi di Roma Unitelma Sapienza, 00161 Rome, Italy

5. Breast Cancer Center. Fondazione Policlinico Universitario Agostino Gemelli, IRCCS, 00168 Rome, Italy

6. Department of Surgery, Università Cattolica del Sacro Cuore, 00168 Rome, Italy
\end{abstract}

ABSTRACT: Sound evidence recognizes the microbiota as one of the major players in human health and disease, including cancer. Every human being is an holobiont, a shared human and microbial ecosystem, in which microbial composition is individually set by behaviours and environmental factors during the first years of life. Thereafter it is modulated by diet, physical activity, emotions and drugs (in particularly antibiotics and chemotherapeutics). As a consequence, a shift in medicine is needed toward a more comprehensive practice that takes into account every individual's genoma and, in addition, his or her metagenome, known as microbiome: a "microbiota revolution". As regards breast cancer (BC), a clear link between microbiota and oncogenesis is still to be confirmed. Specific microbes display unique features regulating their host niche in a number of body sites, which can result in an increased risk of cancer; in addition, gut microbiota composition plays a role in immune modulation within the intestinal barrier, affecting local and systemic inflammation, recognized drivers of cancer. Moreover, part of the bacterial gene mass inside the gut, constituting the so called "estrobolome", influences the sexual hormonal balance and subsequentely may impact on the onset, progression and treatment of hormonal dependent cancers. Microbiota is also clearly involved in modulating the response to anticancer treatments, and above all to the emerging immunotherapy. Based on these premises, the microbiome is becoming a potential target, in order to enhance efficacy of antitumoral treatments as well as to lower their toxicity. The complex scenario that links microbiome composition to oncogenesis and response to anticancer treatments defines the frames of a new "oncobiotic" perspective.

KEYWORDS: Microbiome, Personalized Medicine, Integrative Oncology, Oncobiotic 


\section{INTRODUCTION}

Human microbiota includes organisms belonging to the domains of Bacteria, Archea, Eukarya and viruses, living in almost every site of our body (mostly in the gut, skin, vagina and mouth), in a number far exceeding our own human cells $\mathrm{s}^{1-3}$.

The increasing interest in structure and functions of human-associated microbial communities led the scientific community to build up a consortium, called "Human Microbiome Project (HMP), with the goal to analyse signature microbes in a large cohort of healthy subjects ${ }^{4}$. Each organ inside the body has its own specific microbiota composition, with a relevant inter-individual heterogeneity and different functions affecting physiologic activities, such as metabolism, immune system modulation and overall homeostasis.

Many factors, such as race, diet, maternal colonization, exercise, exposition to xenobiotics contribute to microbiome's individual composition, estabilished during the first years of childhood, and continue to influence its balance all life long ${ }^{5-6}$.

Any perturbation of the microbiota's balance seems to have consequences for the host's homeostasis ${ }^{7}$, potentially leading to metabolic disorders, allergies, inflammatory and autoimmune diseases ${ }^{8}$.

Human microbiota plays a determinant role in the regulation of the innate and cellmediated immunity, including the immune response against pathogenic organisms, through the intestinal barrier ${ }^{5,9}$. Microbes are also involved in metabolism of vitamins and xenobiotics, including anticancer drugs, modulating their pharmacokinetics, mechanism of action and toxicity ${ }^{10}$.

Recently, sound evidences have linked microbiota to cancer development, progression and aggressiveness in different body sites, such as the stomach, colon, skin and lung, at least in 16-18\% of cases ${ }^{7,9,11,12,13,14,15,16,17}$, but its role in $\mathrm{BC}$ is still poorly understood.

Even though our knowledge is scarce, we know that metabolism, sexual hormones, stress management and immunity, in addition to breast tissue microenvironment, play a significant role in the onset and prognosis of $\mathrm{BC}$.

In this review, we try to summarize the current evidence for the potential role of microbiota in each one of these aspects and explore correlations between gut microbiota and $\mathrm{BC}$ supporting a potential gut-breast axis (Fig.1). 


\section{Microbiota and Breast Cancer}

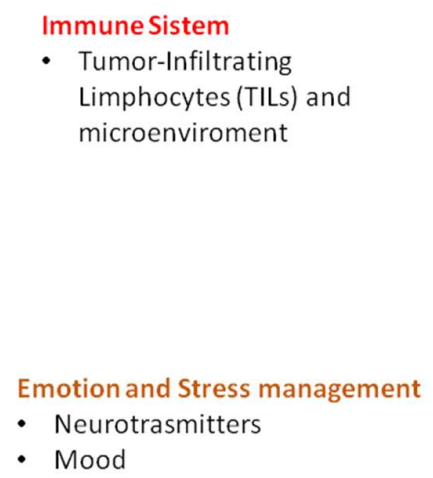

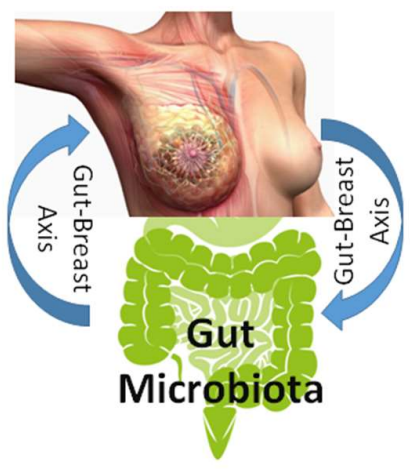

Breast tissue microbiota

- Breast microbe composition
Metabolism and Diet

- Metabolic Sindrome

- Inflammatory Citokynes

- Growth Factors (IGF-1; GH)

Sexual Hormones

- Estrobolome

- Estrogen bioavailability

Fig. 1. Correlations between gut microbiota and breast cancer supporting a potential gut-breast axis.

\section{MICROBIOTA AND CANCER}

The cancerogenesis is the result of genetic and environmental factors, among which chronic inflammation, cytokines and oxidative stress play a key role ${ }^{18}$. Gut microbiota is involved in many chronic inflammatory conditions ${ }^{20}$ and is already recognized as an orchestrator in mechanisms related to tumor onset and progression, at least in animal models and gastro-intestinal cancers ${ }^{21,22,23}$. For instance, microbial products such as colibactin produced by Escherichia coli ${ }^{24}$ and cytolethal distending toxin (CDT) produced by different proteobacteria, cause DNA damage in mammalian cells, promoting colorectal carcinogenesis ${ }^{25,26}$.

Oncogenic type 1 strains of Helicobacter pylori produce a protein (Cag A) that, when injected into the host cell's cytoplasm, can promote cancer by acting on $\beta$-catenin, through the up-regulation of genes involved in proliferation, cell survival and migration, angiogenesis and carcinogenesis.

Numerous microbes, such as the colon cancer associated Fusobacterium nucleatum, activate NF-kB, a major regulator of inflammation within the tumor microenvironment ${ }^{27}$.

Dietary fibre fermentation leads to the production of SCFAs (propionic, acetic and butyric acid are the most common ones), which reduce the inflammatory state of myeloid cells and regulate $\mathrm{T}$ cells in colon, improving intratumoral inflammation $28,29,30$. 
In addition, several microbial enzymes, encoded by major taxa, including hydrolases, lyases, oxidoreductases, glucuronidases and transferases are involved in the metabolism of nutrients, food additives, drugs and environmental pollutants related to cancerogenesis ${ }^{31}$.

More recently, emerging evidence links dysbiosis to cancer onset in extra-intestinal sites, by promoting systemic inflammation ${ }^{32,33}$, modulating immune system and influencing host's metabolites derived from diet and xenobiotics.

Based on these premises, there is a growing interdisciplinary interest to achieve a deeper understanding of host-microbiome interactions for an integrative approach to cancer patients $^{34,35}$.

Even breast cancer's onset and progression are regulated by genetic and environmental factors such as obesity, lack of exercise, alcohol, radiations, hormonal replacement therapy. Individual behaviors have also direct implications in microbiome composition, so that recent studies have highlighted the association between microbial alterations and those risk factors for BC, through metabolic and immunitary pathways ${ }^{36}$, hormonal balance and cancer microenvironment ${ }^{37}$.

More recently, the role of breast tissue's microbiota in $\mathrm{BC}$ is emerging. Microbiome's signatures differ between a breast tumor and healthy tissue, but it is still unclear whether breast dysbiosis is a consequence or a cause of carcinogenesis $^{38,39,40,41}$. Furthermore, the total bacterial DNA load was reduced in tumor versus paired healthy breast tissue, and inversely correlated with advanced disease. This evidence could suggest that more than single species associated with $\mathrm{BC}$, like in the infective diseases model, cancerogenesis might depend on a multimodal model based on bacterial diversity and competition.

\section{GUT-BREAST AXIS AND BREAST TISSUE MICROBIOTA}

Despite the presence of a specific microbiota in human milk has been known for several years ${ }^{42}$, only in the last few years has breast tissue microbiota been evaluated irrespective of lactation and in correlation with cancer ${ }^{43,44,45,46,47}$. These works agree that breast tissues have a unique microbiota, distinct from other body sites, characterized by a predominance of Proteobacteria as the most abundant phylum, followed by Firmicutes ${ }^{43,46}$.

In a study on 20 breast cancer patients, comparing tumoral breast tissues and the normal adjacent ones, the five most represented phyla were Proteobacteria, Firmicutes, Actinobacteria, Bacteroidetes and Verrucomicrobia and a greater amount of Methylobacterium radiotolerans was seen in tumor tissue, while Sphingomonas yanoikuyae was relatively enriched in non-cancerous one ${ }^{44}$. 
A study analyzing breast tissue sampled with 16S rRNA sequencing from two populations of 81 women in Canada and Ireland found proteobacteria as the principal phylum. The most abundant taxa were quite different in the two populations, resulting Bacillus (11.4\%) prevalent in the Canadian samples, while Enterobacteriaceae (30.8\%) in the Irish women ${ }^{43}$. Costantini et al. showed that the genus Ralstonia is the most representative in breast surgical and needle biopsies performed in a Mediterranean population ${ }^{49}$.

In other similar studies, it was seen that tumoral cells were colonized by Streptococcus pyogenes and Lactobacillus rossiae, which interfere in estrogen metabolism and cellular maturation. In addition, Listeria fleischmannii influences the genes regulating the epithelial-mesenchymal transition process, while Haemophilus influenza, which was found in the adjacent non-cancerous tissue samples, promotes the inflammatory immune response and tumor growth ${ }^{48}$.

More recent studies showed that, in women affected by BC, the microbiota of normal breast tissues is more similar to adjacent tumour tissue than to the one sampled from healthy women ${ }^{50}$, supporting the hypothesis that breast tissue dysbiosis may be antecedent to carcinogenic event ${ }^{49}$ and could establish a microenvironment prone to cancer.

To date, there is no clear proof of how bacteria get to the breast tissue.

In addition to the entrance from the nipple, some studies suggest the presence of a gut-breast axis, along which the intestinal bacteria could reach the mammary gland ${ }^{51}$. This endogenous route of bacterial translocation should involve dendritic cells, which can sample bacteria directly from the gut lumen or after passing through the intestinal barrier, priming T cells in the Peyer's patches or after reaching the mesenteric lymph nodes $^{52}$.

Albesharat et al showed the same bacteria strains in maternal milk and faeces from mother and her child, suggesting a vertical transfer of intestinal bacteria from the mother's gut to her milk and subsequently to the new-born ${ }^{53}$. Further studies showed that mammary intestinal dysbiosis may lead to lactational mastitis, induced by opportunistic pathogenic bacteria outgrowing the commensal germs ${ }^{54}$ and orally administered probiotics isolated from human milk may be proven more effective than antibiotics in treating mastitis itself ${ }^{55}$. Furthermore, the isolation of strains of Enterococcus, Streptococcus, Staphylococcus, and Propionibacterium in neonatal umbilical cord blood of caesarean-born babies further support the idea that bacteria can reach the mammary ducts via the bloodstream ${ }^{56}$.

Following this pathway, a gut inflammatory process, driven by intestinal dysbiosis, through an impaired intestinal barrier or "leaky gut", may lead to systemic chronic condition and eventually to carcinogenesis, sustained by overexpression of COX2 and increased production of prostaglandins, as showed in several preclinical and clinical studies ${ }^{57}$. 
The chronic inflammation-based cancerogenesis seems to be driven by a multiagent and multifactorial process rather than a single germ mechanism.

Xuan and colleagues found that breast tumour tissues had a significantly reduced amount and richness of bacteria compared to healthy controls ${ }^{47}$.

In a case-control study in post-menopausal women with $\mathrm{BC}$, fecal microbiota showed less diversity and overall different composition compared to controls ${ }^{58}$, suggesting an involvement of microbiome composition in $\mathrm{BC}$ cancerogenesis ${ }^{47}$.

Even for non-malignant or premalignant breast diseases, such as mastitis or atypical ductal hyperplasia, lower microbial diversity seems to play a role, by promoting increased growth of opportunistic pathogens ${ }^{54}$, which could pave the way for a potential use of breast tissue dysbiosis assessment as predictive tool and of prebiotics/probiotics in precancerous conditions, in order to prevent cancer development.

\section{MICROBIOTA AND IMMUNE SYSTEM}

Microbiota is a key player in the induction, training and functioning of the host's immune system.

The components of the innate and adaptive immune system, through a symbiotic relationship and a continuous cross-talk with different microbial communities, allow protective responses against foreign antigens and pathogens while providing tolerance to harmless antigens and commensal bacteria ${ }^{59}$.

This alliance between immune system and microbiota takes place mainly in the skin and the gastrointestinal tract with its associated lymphoid tissue (GALT), where the largest populations of immune cells and commensal germs reside.

In the gut, the mucosal wall, constituted by the combined action of epithelial cells, mucus layer, IgA and antimicrobial peptides, has a fundamental role in recognizing healthy nutrients and potential noxae, avoiding the microbial translocation through the barrier and promoting the postnatal development of the immune system ${ }^{60,61,62,}$.

When major changes in gut microbiota's composition and diversity occur, following stressful chronic conditions, poor diet, lack of exercise or antibiotics abuse, immunemediated diseases, such as colitis and inflammatory bowel disease (IBD) may take place.

The compromised intestinal barrier in individuals with chronic gut dysbiosis leads to submucosal translocation of bacteria, triggering persistent activation of immunemediated inflammatory responses, both at a local and systemic level, eventually 
leading to cancer of the colon and/or in extraintestinal sites. This cancerogenic process may be mediated by inflammatory cytochines, bacterial metabolites and regulatory $\mathrm{T}$ cells inhibition, but could also be due to direct translocation of pathogenic germs to distant organs and tissues.

The emergent role of immune microenviroment in $\mathrm{BC}$, and above all of tumourinfiltrating lymphocytes (TILs), makes the tight relationship between microbiota and the interplay between proinflammatory and antinflammatory immune mediators a promising field of translational and clinical research in $\mathrm{BC}^{65}$.

TILs are recognized as a prognostic indicator, for example in triple-negative $\mathrm{BC}$ (TNBC), and are associated with disease-free (DFS) and overall survival (OS).

Results from two phase III randomized adjuvant trials (ECOG 2197 and ECOG 1199) conducted on 481 cancer patients, with a median follow-up of 10.6 years, showed higher stromal TILs scores associated with better prognosis. In particular, for every $10 \%$ increase in TILs, a $18 \%$ reduction of risk of distant recurrence $(\mathrm{p}=.04)$, and $19 \%$ reduced risk of death $(\mathrm{p}=.01)$ were observed $^{66}$.

In recent times, immunotherapy is emerging as a promising strategy against hematopoietic and solid tumors which do not respond to conventional therapies ${ }^{67,68}$.

The rationale of this treatment is that immune system surveillance can be reactivated by blocking the expedients used by cancer cells to evade the antitumor response ${ }^{67,69,70}$.

Unfortunately, a significant heterogeneity of immune response to this kind of treatments exists; moreover, immune checkpoint inhibitors (ICI) may generate immune-related adverse effects, in particular colitis and pituitary gland inflammation in response to CTLA4 antibodies, and thyroid dysfunction and pneumonitis following blockade of the PD1-PDL1 interaction.

In this scenario, gut microbiota seems to play an important role, and a manipulation of the microbical colonies and their composition, through antibiotics, prebiotics or probiotics, can influence either the efficacy of immunotherapeutics ${ }^{71,72,73,74}$ and their toxicity ${ }^{75}$.

Gut microbiota, through TLR4 signalling, stimulate myeloid and tumor infiltrating cells for responsiveness to intratumoral treatment with the TLR9 agonist CpGoligodeoxynucleotide $(\mathrm{CpG}-\mathrm{ODN})^{73,76,77,78}$. CpG-ODNs induce myeloid cells to 
produce proinflammatory citokines, such as tumour necrosis factor (TNF) and IL-12, in a proportional manner with the presence of Gram-negative Alistipes and Grampositive Ruminococcus genera in fecal microbiota of mice. On the other hand, Lactobacillus genus is negatively correlated to these cytokines' production ${ }^{79}$. It was also seen that recolonization of Alistipes shahii after antibiotic therapy leads myeloid cells to regain the ability of producing TNF, while oral somministration of L. fermentum inhibits TNF synthesis ${ }^{73}$.

In a study ${ }^{80}$ including 249 patients with different types of cancer (melanoma, lung, kidney, bladder) treated with ICIs, patients affected by antibiotic-induced dysbiosis, with a significant reduction of the genus Akkermansia muciniphila in fecal samples, showed a general reduction of therapeutic response to anti PD-1 / PDL-1 and consequently a lower progression-free survival of the disease (PFS) and total survival (OS). To test the effective correlation between Akkermansia muciniphila and the response to ICIs, germ-free mice models, receiving faecal microbiota from respondents with marked presence of Akkermansia muciniphila, demonstrated a superior therapeutic response, a significant reduction in tumor size and increased immune cells accumulation in cancer microenvironment.

In a recent prospective study ${ }^{81}$, Spencer et al showed that in 146 melanoma patients, probiotics and antibiotics use at baseline were associated with lower alpha diversity (AD) in stool samples $(\mathrm{p}=0.02)$ and patients with higher consume of plant based diet had higher odds of response to immunotherapeutics ( $\mathrm{OR}=5.3,95 \% \mathrm{CI}$ : 1.02-26.3).

\section{MICROBIOTA AND METABOLISM}

Metabolic syndrome, obesity and insulin resistance significantly affect BC incidence and mortality, especially among post-menopausal women ${ }^{82,83}$.

Gut microbiota composition is a major player of intestinal barrier integrity, inflammation and obesity, as shown in germ-free mice models after fecal transplant from obese people ${ }^{84,85}$. 
For instance, a fecal abundance of Ralstonia pickettii was found increased in obese subjects with pre-diabetes and type 2 diabetes mellitus, and Ralstonia pickettii-treated mice showed reduced glucose tolerance. This led the authors to suppose that lowgrade inflammation, potentially initiated by the intestinal microbiota, could be a driving force in the development of insulin resistance in obesity ${ }^{86}$.

Microbial dysbiosis is involved in low-grade chronic inflammation-mediated carcinogenesis, at least in gastric and intestinal cancers ${ }^{87}$, while a clear correlation with BC is still to be confirmed ${ }^{88}$.

An association in mice between gastric infection by pathogenic Helicobaster hepaticus, TNF-alfa expression and rapidly growing tumors in mammary tissue has been showed ${ }^{89}$, which is consistent with the findings of elevated TNF-alfa and poor $\mathrm{BC}$ outcomes in women.

Similarly, Akkermansia muciniphila levels and inflammatory cytokine IL6, associated with BMI in obese BC patients, lead to poorer clinical outcomes ${ }^{90}$. The loss of Akkermansia muciniphila allows the lipopolysaccharide (LPS) and other endotoxins to leak, through an altered intestinal barrier, into the blood stream, causing chronic inflammation in different districts of the body, including breast tissue.

On the contrary, abundance in the gut of Bifidobacterium and Faecalibacterium Prausnitzii following a plant based diet is associated with anti-inflammatory and antitumoral effects ${ }^{91,92}$.

The gut microbiota is also involved in the production of a large amount of metabolites, that might interfere with cancerogenesis in extraintestinal cancers, including BC.

Most of these metabolites derive from aminoacidic metabolism, but the exact relations between proteic dietary intake and microbiome's manipulation are yet to be established.

Among the most studied microbiota derived metabolites, trimethylammine (TMA) and its oxidated form (TMAO) stand for a perfect example of diet-microbiota interaction: phosphatidylcholine and L-carnitine, aboundant in red meat, are metabolized in TMA by several intestinal bacterial species and oxidated by the liver to TMAO, whose plasma levels are associated to progression of atherosclerosis, platelet aggregation and certain cancer types, probably through inflammatory pathways $^{93,94,95,96}$.

Microbiota's composition and functions are modulated by nutrients introduced with diet: vegan people are endowed with a microbiota which poorly produces TMA, even when its precursors are occasionally consumed ${ }^{93}$. On the contrary, patients who undergo bariatric surgery show high levels of circulating TMAO, probably as a result of an aerobic gut environment, the perfect condition for the production of this metabolite m7,98,99,100. $^{9}$. 
In a recent study, early stage BC patients had reduced abundance in fecal DNA of genes responsible for bacterial cadaverine production, as compared to healthy women; the microbiome derived cadaverine affects the behavior of $\mathrm{BC}$ cells, showing a tumor suppressor role ${ }^{101}$.

In addition, short chain fatty acids (SCFAs), products of bacterial fermentation of complex polysaccharides in the distal gut, are well known modulators for cell invasion, apoptosis and outcomes in $\mathrm{BC}^{102,103,104,105,106,107}$. Other bacterial metabolites, such as lithocholic acid produced in the small intestine and colon by commensal germs, can stimulate oxidative and nitrosative stress, thus inhibiting BC progression and metastases and are involved in cellular signaling, by binding to G-proteincoupled bile acid receptor 1 (also known as TGR5) and receptor FXR ${ }^{108,109,110}$. Both TGR5 and FXR regulate important metabolic pathways, related to the risks of obesity, steatosis, impaired tolerance to glucose and insulin resistance, generally recognized as risk factors for $\mathrm{BC}^{108,110,111,112,113,114}$.

\section{ESTROBOLOME}

Gut microbiome is one of the major regulators of circulating estrogens ${ }^{115,116}$, which are involved in the onset, progression and outcomes of the majority of breast cancers $^{117,118}$. Sexual hormones are normally conjugated and excreted by the liver into the intestinal lumen, where particular species of bacteria, constituting the so called "estrobolome", endowed with $\beta$-glucuronidase activity, may deconjugate estrogens, increasing their reabsorption through the entero-epathic circulation.

Common bacteria in human microbiota provided with the $\beta$-glucuronidase enzyme include Collinsella, Edwardsiella, Alistipes, Bacteroides Bifidobacterium, Citrobacter, Clostridium, Dermabacter, Escherichia, Faecalibacterium, Lactobacillus, Marvinbryantia, Propionibacterium, Roseburia, Tannerella119,120,121 .

Changes in estrobolome composition induced by lifestyles and drugs, including antibiotics, modify systemic levels of estrogen and its metabolites, even in hormonal dependent BC patients and survivors ${ }^{122,123,124}$. Several studies link BC progression to the entero-hepatic circulation of estrogens ${ }^{126}$, and an abundance of $\beta$-Glucuronidase signaling was identified in nipple aspirate fluid of $\mathrm{BC}$ survivors ${ }^{126}$, while $\mathrm{BC}$ tissue shows higher concentrations of estrogen metabolites compared to normal breast tissue $^{127}$.

A small study comparing 10 premenopausal women, consuming a "Western diet" (with high fat intake), with 10 vegetarians with a high fiber and moderate fat diet, showed estrogen levels three times higher in vegetarians' feces and $15 \%$ to $20 \%$ lower in serum ${ }^{128}$. In another study, immigrants from Asia, consuming a low fat diet, had systemic estrogen levels 30\% lower than American women eating a high-fat $\operatorname{diet}^{129}$, possibly via the estrobolome, although additional factors including lifestyle, exercise and supplements may contribute ${ }^{130}$. 
Intestinal bacteria can turn some plant lignans into mammalian lignans, enterodiol and enterolactone, which may act as selective modulators of estrogens with protective effects against $\mathrm{BC}^{131,132}$, and improve survival in postmenopausal $\mathrm{BC}$ patients ${ }^{133}$.

On the other hand, sex hormones affect the gut's microbiome and estrogen deprivation following menopause could be responsible for major modifications of microbiota composition later in women's life.

Furthermore, gut microbiota contributes to the metabolism of endocrine disrupting chemicals, such as bisphenol-A, affecting their plasmatic levels and toxicodynamics ${ }^{135}$. This mechanism might have a deep impact on clinical management of $\mathrm{BC}$ patients, since the emerging evidence of an association between exposure to endocrine disruptor chemicals, metabolic disorders, diabetes and cancer ${ }^{136}$.

\section{MICROBIOTA AND EMOTIONS}

Emerging evidence is linking microbiome's composition with different outcomes in psycho-social behaviors and emotions ${ }^{137}$, which evoke endocrine and metabolic responses involved in maintaining health, favoring adaptation to the environment and predisposition for chronic diseases.

Microbiota-gut-brain axis, a bridge between lifestyle habits, gastro-intestinal functions and mental health, includes several pathways and communicates via the immune system, direct enteric nervous system routes and bacterial metabolites.

Many BC patients experience cancer-related distress symptoms, anxiety and depression, during and after oncological treatments ${ }^{138}$. Negative emotions and prolonged stress stimulate the production of pro-inflammatory cytokines and the release of corticotrophin, adrenaline, noradrenaline and cortisol by the hypothalamicpituitary-adrenal (HPA) axis ${ }^{139,140,141,142,143}$. These stress-related hormones act as growth factors for pathogens such as E. coli (E. coli0157), Yersinia enterocolitic and Pseudomonas aeruginosa that increase the synthesis of pro-inflammatory cytokines $^{144}$.

While the influence of mind on gut's functioning is intuitive and well estabilished ${ }^{145}$, the role that gut microbiota plays on mental health is less clear and self-evident. Yet, dysbiosis driven by alterations of the brain reward system and bad behaviors (namely, lack of exercise and overcomsumption of red meats and ultraprocessed foods) can be responsible for poor psycho-social outcomes and stress-related disorders ${ }^{146,147,148}$.

Patients with functional gastro-intestinal disorders (FGIDs) produce a great amount of cortisol ${ }^{149}$, are more prone to hypersensibility phenomena such as pain ${ }^{150}$ and present higher levels of anxiety and depression. 
Pathogenic microbes, overgrowing in patients with dysbiosis, produce toxins, which are released into the blood stream ${ }^{151,152,153}$, directly influencing mental health and mood disorders, such as butyrate-producing Faecalibacterium bacteria ${ }^{154}$. Gut microbiota is also able to produce other neurotransmitters, recognized through the faecal metagenome analysis, such as serotonin, norepinephrine, dopamine, 3,4dihydroxyhenylacetic acid and gamma-aminobutyric acid (GABA), positively associated to anxiety and depression.

Scientific evidences suggest a link between mental health and other microbiome derived metabolites, like bile acids ${ }^{155}$, acetic acid and propionic acid ${ }^{156}$, volatile organic metabolites ${ }^{157}$, fecal proteases ${ }^{158}$, lactate, pyruvate ${ }^{159}$, amino acids ${ }^{160}$ (alanine, pyroglutamic acid), tyrosine, lysine, leucine ${ }^{159}$, phenols ${ }^{160}$, polyunsaturated fatty acids (PUFAs) $)^{161}$ and short chain fatty acids (SCFAs) ${ }^{162}$.

Several studies ${ }^{163,164,165}$ have also shown that stress-induced and estrogen-induced visceral pain is linked to epigenetic modification at the spinal cord, mediated by SCFAs. In other terms, gut-microbial products can affect chromatin plasticity in host's brain, leading to potential changes in neuronal transcription and eventually host behaviours ${ }^{166}$.

In an interesting study, gut microbiome diversity, assessed in fecal samples, was associated to better psycho-social outcomes in BS survivors, with less anxiety, depression and fatigue ${ }^{167}$.

The increasing rates of long-term survival in women affected by $\mathrm{BC}$ impose quality of life and mental health as absolute needs to be addressed properly. Furthermore, an appropriate management of mental health issues in BC patients, frequently facing gastrointestinal disorders, psychological distress, anxiety and depression, is mandatory not only for their quality of life, but also for potential implications in cancerogenesis and oncologic outcomes, through processes mediated by immune imbalance and proinflammatory citokines. Based on these premises, a new frontier of research is studying how microbiota modulation could contribute to neuropsychological adjustments ${ }^{168,169}$ in BC women undergoing oncological treatments.

\section{CONCLUSIONS}

Many relevant evidences are unveiling profound links between human microbiota composition and several physiological and pathological processes, including cancer.

While gut dysbiosis is clearly linked by a cause-effect relation to many diseases and pathological conditions, it is still unclear whether the recent evidence of breast tissue dysbiosis represents a cause or a consequence of cancer.

The recognition of individual microbical profiles in every human being is driving a new model of precision oncology, tailored not only to genetic features of the subject 
and the cancer itself, but also to his or her microbiome signatures, and will orientate preventive and predictive measures in the next future.

Given this key role of microbical communities and their plasticity, i.e. the possibility to be modulated through behavioral changes and antibiotic, prebiotics and probiotics, microbiota must be considered a potential target in order to enhance efficacy, reduce toxicities and alleviate side effects of antitumoral therapies.

In addition, microbiome manipulation becomes strategic in order to empower immunitary, metabolic, hormonal and psychological approaches to cancer patients and further improve oncologic outcomes.

As regards $\mathrm{BC}$, microbiota is involved in several pathways, from intestinal patterns of metabolic syndrome, to immune system modulation, sexual hormones balance and bioavailability, stress management and directly through breast tissue dysbiosis.

Advancing this brand new oncobiotic science will probably lead us to significant improvements in the fight against cancer for the years to come.

\section{FUNDING}

This research received no external funding.

INSTITUTIONAL REVIEW BOARD STATEMENT

Not applicable.

INFORMED CONSENT STATEMENT

Not applicable.

CONFLICTS OF INTEREST

The authors declare no conflict of interest. 


\section{BIBLIOGRAPHY}

1. Ley RE, Peterson DA, Gordon JI. Ecological and evolutionary forces shaping microbial diversity in the human intestine. Cell 124: 837-848, 2006.

2. Savage DC. Microbial ecology of the gastrointestinal tract. Annu Rev Microbiol 31: 107-133, 1977.

3. Whitman WB, Coleman DC, Wiebe WJ. Prokaryotes: the unseen majority. Proc Natl Acad Sci USA 95: 6578-6583, 1998.

4. Huttenhower, C., Gevers, D., Knight, R., Abubucker, S., Badger, J. H., Chinwalla, A. T., ... \& Giglio, M. G. (2012). Structure, function and diversity of the healthy human microbiome. nature, 486(7402), 207.

5. Keku T.O., Dulal S., Deveaux A., Jovov B., Han X. The gastrointestinal microbiota and colorectal cancer. Am. J. Physiol. Gastrointest. Liver Physiol. 2015.

6. Turnbaugh P.J., Hamady M., Yatsunenko T., Cantarel B.L., Duncan A., Ley R.E., Sogin M.L., Jones W.J., Roe B.A., Affourtit J.P., et al. A core gut microbiome in obese and lean twins. Nature. 457:480-484, 2009

7. Schwabe, R. F., \& Jobin, C. (2013). The microbiome and cancer. Nature Reviews Cancer, 13(11), 800-812.

8. Selber-Hnatiw S., Rukundo B., Ahmadi M., Akoubi H., Al-Bizri H., Aliu A.F., Ambeaghen T.U., Avetisyan L., Bahar I., Baird A., et al. Human Gut Microbiota: Toward an Ecology of Disease. Front. Microbiol. 8:1265, 2017

9. Rea D., Coppola G., Palma G., Barbieri A., Luciano A., Del Prete P., Rossetti S., Berretta M., Facchini G., Perdonà S., et al. Microbiota effects on cancer: From risks to therapies. Oncotarget. 9:17915-17927 2018.

10. Dzutsev, A., Badger, J. H., Perez-Chanona, E., Roy, S., Salcedo, R., Smith, C. K., \& Trinchieri, G. (2017). Microbes and cancer. Annual review of immunology, 35, 199-228.

11. Lofgren J.L., Whary M.T., Ge Z., Muthupalani S., Taylor N.S., Mobley M., Potter A., Varro A., Eibach D., Suerbaum S., et al. Lack of commensal flora in Helicobacter pylori-infected INS-GAS mice reduces gastritis and delays intraepithelial neoplasia. Gastroenterology. 140:210-220; 2011

12. Couturier-Maillard A., Secher T., Rehman A., Normand S., De Arcangelis A., Haesler R., Huot L., Grandjean T., Bressenot A., Delanoye-Crespin A., et al. NOD2-mediated dysbiosis predisposes mice to transmissible colitis and colorectal cancer. J. Clin. Investig. 123:700-711, 2013

13. Dapito D.H., Mencin A., Gwak G.Y., Pradere J.P., Jang M.K., Mederacke I., Caviglia J.M., Khiabanian H., Adeyemi A., Bataller R., et al. Promotion of 
hepatocellular carcinoma by the intestinal microbiota and TLR4. Cancer Cell. 21:504-516, 2012.

14. Yan X., Yang M., Liu J., Gao R., Hu J., Li J., Zhang L., Shi Y., Guo H., Cheng J., et al. Discovery and validation of potential bacterial biomarkers for lung cancer. Am. J. Cancer Res. 2015;5:3111-3122.

15. De Martel C., Ferlay J., Franceschi S., Vignat J., Bray F., Forman D., Plummer M. Global burden of cancers attributable to infections in 2008: A review and synthetic analysis. Lancet Oncol. 13:607-615, 2012.

16. Shreiner, A. B., Kao, J. Y., \& Young, V. B. (2015). The gut microbiome in health and in disease. Current opinion in gastroenterology, 31(1), 69.

17.Bhatt, A. P., Redinbo, M. R., \& Bultman, S. J. (2017). The role of the microbiome in cancer development and therapy. CA: a cancer journal for clinicians, 67(4), 326-344.

18. Hooper LV, Littman DR, Macpherson AJ. Interactions between the microbiota and the immune system. Science. 336(6086):1268-73, 2012

19. Mellman I, Coukos G, Dranoff G Cancer immunotherapy comes of age. Nature. 480(7378):480-9, 2011

20. Ferreira, C. M., Vieira, A. T., Vinolo, M. A. R., Oliveira, F. A., Curi, R., \& Martins, F. D. S. (2014). The central role of the gut microbiota in chronic inflammatory diseases. Journal of immunology research, 2014.

21. David H. Rudolf Virchow and modern aspects of tumor pathology. Pathol Res Pract, 183 pp. 356-364, 1988

22. Cho I, et al. Antibiotics in early life alter the murine colonic microbiome and adiposity. Nature. 488:621-626, 2012

23. Armstrong, H., Bording-Jorgensen, M., Dijk, S., \& Wine, E. (2018). The complex interplay between chronic inflammation, the microbiome, and cancer: understanding disease progression and what we can do to prevent it. Cancers, 10(3), 83.

24. Nougayrède JP, Homburg $\quad$ S, Taieb $\quad F$, Boury $\quad$ M, Brzuszkiewicz E, Gottschalk G, Buchrieser C, Hacker J, Dobrindt U, Oswald E. Escherichia coli induces DNA double-strand breaks in eukaryotic cells. Science. 313(5788):848-51, 2006

25.Arthur JC, Gharaibeh RZ, Mühlbauer M, Perez-Chanona E, Uronis JM, McCafferty J, Fodor AA, Jobin C6. Microbial genomic analysis reveals the essential role of inflammation in bacteria-induced colorectal cancer.Nat Commun. 3;5:4724, 2014 
26. Arthur JC, Perez-Chanona E, Mühlbauer M, Tomkovich S, Uronis JM, Fan TJ, Campbell BJ, Abujamel T, Dogan B, Rogers AB, Rhodes JM, Stintzi A, Simpson KW, Hansen JJ, Keku TO, Fodor AA, Jobin C. Intestinal inflammation targets cancer-inducing activity of the microbiota. Science. 338(6103):120-3, 2012

27. Kostic AD1, Chun E, Robertson L, Glickman JN, Gallini CA, Michaud M, Clancy TE, Chung DC, Lochhead P, Hold GL, El-Omar EM, Brenner D, Fuchs CS, Meyerson M, Garrett WS Fusobacterium nucleatum potentiates intestinal tumorigenesis and modulates the tumor-immune microenvironment. Cell Host Microbe. 14(2):207-15, 2013

28. Maslowski KM, Vieira AT, Ng A, Kranich J, Sierro F, Yu D, Schilter HC, Rolph MS, Mackay F, Artis D, Xavier RJ, Teixeira MM, Mackay CR. Regulation of inflammatory responses by gut microbiota and chemoattractant receptor GPR43. Nature. 461(7268):1282-6, 2009

29.Smith PM, Howitt MR, Panikov N, Michaud M, Gallini CA, Bohlooly-Y M, Glickman JN, Garrett WS. The microbial metabolites, short-chain fatty acids, regulate colonic Treg cell homeostasis. Science. 341(6145):569-73, 2013

30. Furusawa Y, Obata Y, Fukuda S, Endo TA, Nakato G, Takahashi D, Nakanishi Y, Uetake C, Kato K, Kato T, Takahashi M, Fukuda NN, Murakami S, Miyauchi E, Hino S, Atarashi K, Onawa S, Fujimura Y, Lockett T, Clarke JM, Topping DL, Tomita M, Hori S, Ohara O, Morita T, Koseki H, Kikuchi J, Honda K, Hase K, Ohno H. Commensal microbederived butyrate induces the differentiation of colonic regulatory $\mathrm{T}$ cells. Nature. 504(7480):446-50, 2013

31. Koppel, N., Rekdal, V. M., \& Balskus, E. P. (2017). Chemical transformation of xenobiotics by the human gut microbiota. Science, 356(6344).

32. Tilg H., Moschen A.R. Food, immunity, and the microbiome. Gastroenterology, 148, pp. 1107-1119, 2015

33. Rajpoot M, Sharma AK, Sharma A, Gupta GK. Understanding the microbiome: emerging biomarkers for exploiting the microbiota for personalized medicine against cancer. Semin Cancer Biol 2018

34.Helmink, B. A., Khan, M. W., Hermann, A., Gopalakrishnan, V., \& Wargo, J. A. (2019). The microbiome, cancer, and cancer therapy. Nature medicine, 1.

35. Magno, S., Filippone, A., \& Scaldaferri, A. (2018). Evidence-based usefulness of integrative therapies in breast cancer. Translational Cancer Research, 7(3), S379-S389 
36. Kovács, T., Mikó, E., Vida, A., Sebő, É., Toth, J., Csonka, T., ... \& Bai, P. (2019). Cadaverine, a metabolite of the microbiome, reduces breast cancer aggressiveness through trace amino acid receptors. Scientific reports, 9(1), 114.

37. Parida, S., \& Sharma, D. (2020). Microbial Alterations and Risk Factors of Breast Cancer: Connections and Mechanistic Insights. Cells, 9(5), 1091.

38.Daniel H, Gholami AM, Berry D, Desmarchelier C, Hahne H, Loh G, Mondot S, Lepage P, Rothballer M, Walker A, et al. High-fat diet alters gut microbiota physiology in mice. ISME J. 8:295-308, 2014

39.Tulloch AJ, Murray S, Vaicekonyte R, Avena NM. Neural responses to macronutrients: hedonic and homeostatic mechanisms. Gastroenterology. 148:1205-1218, 2015

40.Fox SI. Regulación del metabolismo. In: Fox SI. Fisiología humana. 10th ed. Madrid: McGraw Hill; 637-657, 2008

41. Singh M. Mood, food, and obesity. Front Psychol. 5:925, 2014

42.Fernández, L., Langa, S., Martín, V., Maldonado, A., Jiménez, E., Martín, R., \& Rodríguez, J. M. (2013). The human milk microbiota: origin and potential roles in health and disease. Pharmacological research, 69(1), 1-10.

43.Urbaniak, C., Cummins, J., Brackstone, M., Macklaim, J. M., Gloor, G. B., Baban, C. K., ... \& Tangney, M. (2014). Microbiota of human breast tissue. Appl. Environ. Microbiol., 80(10), 3007-3014.

44. Urbaniak, C., Gloor, G. B., Brackstone, M., Scott, L., Tangney, M., \& Reid, G. (2016). The microbiota of breast tissue and its association with breast cancer. Applied and environmental microbiology, 82(16), 5039-5048.

45.Chan A.A., Bashir M., Rivas M.N., Duvall K., Sieling P.A., Pieber T.R., Vaishampayan P.A., Love S.M., Lee D.J. Characterization of the microbiome of nipple aspirate fluid of breast cancer survivors. Sci. Rep. 6:28061, 2016

46. Hieken, T. J., Chen, J., Hoskin, T. L., Walther-Antonio, M., Johnson, S., Ramaker, S., ... \& Degnim, A. C. (2016). The microbiome of aseptically collected human breast tissue in benign and malignant disease. Scientific reports, 6, 30751 .

47.Xuan, C., Shamonki, J. M., Chung, A., DiNome, M. L., Chung, M., Sieling, P. A., \& Lee, D. J. (2014). Microbial dysbiosis is associated with human breast cancer. PloS one, 9(1), e83744.

48. Thompson, K. J., Ingle, J. N., Tang, X., Chia, N., Jeraldo, P. R., WaltherAntonio, M. R., ... \& Kalari, K. R. (2017). A comprehensive analysis of breast cancer microbiota and host gene expression. PloS one, 12(11), e0188873. 
49.Costantini L, Magno S, Albanese D, Donati C, Molinari R, Filippone A, Masetti R, Merendino N. Characterization of human breast tissue microbiota from core needle biopsies through the analysis of multi hypervariable 16SrRNA gene regions, 168932018

50. Wang, H. et al. Breast tissue, oral and urinary microbiomes in breast cancer. Oncotarget 8 (2017).

51. Rescigno, M., Urbano, M., Valzasina, B., Francolini, M., Rotta, G., Bonasio, R., ... \& Ricciardi-Castagnoli, P. (2001). Dendritic cells express tight junction proteins and penetrate gut epithelial monolayers to sample bacteria. Nature immunology, 2(4), 361-367.

52. Perez, P. F., Doré, J., Leclerc, M., Levenez, F., Benyacoub, J., Serrant, P., ... \& Donnet-Hughes, A. (2007). Bacterial imprinting of the neonatal immune system: lessons from maternal cells?. Pediatrics, 119(3), e 724-e732.

53. Albesharat, R., Ehrmann, M. A., Korakli, M., Yazaji, S., \& Vogel, R. F. (2011). Phenotypic and genotypic analyses of lactic acid bacteria in local fermented food, breast milk and faeces of mothers and their babies. Systematic and Applied Microbiology, 34(2), 148-155.

54. Patel, S. H., Vaidya, Y. H., Patel, R. J., Pandit, R. J., Joshi, C. G., \& Kunjadiya, A. P. (2017). Culture independent assessment of human milk microbial community in lactational mastitis. Scientific reports, 7(1), 1-11.

55. Arroyo, R., Martín, V., Maldonado, A., Jiménez, E., Fernández, L., \& Rodríguez, J. M. (2010). Treatment of infectious mastitis during lactation: antibiotics versus oral administration of Lactobacilli isolated from breast milk. Clinical Infectious Diseases, 50(12), 1551-1558.

56. Jiménez, E., Fernández, L., Marín, M. L., Martín, R., Odriozola, J. M., Nueno-Palop, C., ... \& Rodríguez, J. M. (2005). Isolation of commensal bacteria from umbilical cord blood of healthy neonates born by cesarean section. Current microbiology, 51(4), 270-274.

57. Wang, D., \& DuBois, R. N. (2004, February). Cyclooxygenase-2: a potential target in breast cancer. In Seminars in oncology (Vol. 31, pp. 64-73). WB Saunders.

58.Goedert, J. J., Jones, G., Hua, X., Xu, X., Yu, G., Flores, R., ... \& Feigelson, H. S. (2015). Investigation of the association between the fecal microbiota and breast cancer in postmenopausal women: a population-based casecontrol pilot study. JNCI: Journal of the National Cancer Institute, 107(8).

59.Britti, M. S., Roselli, M., Finamore, A., Merendino, N., \& Mengheri, E. (2006). Regulation of immune response at intestinal and peripheral sites by probiotics. Biologia, 61(6), 735-740 
60. Macpherson A.J., Slack E., Geuking M.B., and McCoy K.D. The mucosal firewalls against commensal intestinal microbes. Semin. Immunopathol. 31, 145-149, 2009

61. McGuckin M. A., Linden S. K., Sutton P., Florin T. H. Mucin dynamics and enteric pathogens. Nat. Rev. Microbiol. 9, 265-278. 2011

62.Hooper, L.V., and Macpherson, A.J. Immune adaptations that maintain homeostasis with the intestinal microbiota. Nat. Rev. Immunol. 10, 159-169, 2010

63. Antoni L., Nuding S., Wehkamp J., Stange E. F. Intestinal barrier in inflammatory bowel disease. World J. Gastroenterol. 20, 1165-1179. 2014

64.Tlaskalová-Hogenová $\mathrm{H}$, Stepánková R, Hudcovic $\mathrm{T}$, Tucková L, Cukrowska B, Lodinová-Zádníková R, Kozáková H, Rossmann P, Bártová J, Sokol D, Funda DP, Borovská D, Reháková Z, Sinkora J, Hofman J, Drastich P, Kokesová A.. Commensal bacteria (normal microflora), mucosal immunity and chronic inflammatory and autoimmune diseases. Immunol Lett 93:97-108, 2004.

65. Savas, P., Salgado, R., Denkert, C., Sotiriou, C., Darcy, P. K., Smyth, M. J., \& Loi, S. (2016). Clinical relevance of host immunity in breast cancer: from TILs to the clinic. Nature reviews Clinical oncology, 13(4), 228

66.Adams, S., Gray, R. J., Demaria, S., Goldstein, L., Perez, E. A., Shulman, L. N., ... \& Badve, S. S. (2014). Prognostic value of tumor-infiltrating lymphocytes in triple-negative breast cancers from two phase III randomized adjuvant breast cancer trials: ECOG 2197 and ECOG 1199. Journal of clinical oncology, 32(27), 2959.

67.Couzin-Frankel, J. Breakthrough of the year 2013. Cancer immunotherapy. Science 342, 1432-1433, 2013

68.Sagiv-Barfi D., Czerwinski D.K., Levy S., Alam I.S., Mayer A.T., Gambhir S.S., Levy R.. Eradication of spontaneous malignancy by local immunotherapy. Science Translational Medicine 3:Vol. 10, Issue 426, eaan4488, 2018

69.Rosenberg S. A., Yang J. C., Restifo N. P. Cancer immunotherapy: moving beyond current vaccines. Nat. Med. 10, 909-915 2004

70.Page D. B., Postow M. A., Callahan M. K., Allison J. P., Wolchok J. D. Immune modulation in cancer with antibodies. Annu. Rev. Med. 65, 185202,2014

71.Zitvogel L. Gut microbiome influences efficacy of PD-1-based immunotherapy against epithelial tumors. Science 359, 91-97, 2018 
72.Vétizou, M., Pitt, J. M., Daillère, R., Lepage, P., Waldschmitt, N., Flament, C., ... \& Zitvogel, L. (2015). Anticancer immunotherapy by CTLA-4 blockade relies on the gut microbiota. Science, 350(6264), 1079-1084.

73.Iida, N., Dzutsev, A., Stewart, C. A., Smith, L., Bouladoux, N., Weingarten, R. A., ... \& Goldszmid, R. S. (2013). Commensal bacteria control cancer response to therapy by modulating the tumor microenvironment. Science, 342(6161), 967-970.

74.Sivan A, Corrales L, Hubert N, Williams J.B., Aquino-Michaels K, Earley Z.M., Benyamin F.W., Lei Y.M., Jabri B., Alegre M.L., Chang E.B., Gajewski T.F. Commensal Bifidobacterium promotes antitumor immunity and facilitates anti-PD-L1 efficacy. Science. 350(6264): 1084-1089, 2015.

75. Gedye C, van der Westhuizen A, John T. Checkpoint immunotherapy for cancer: superior survival, unaccustomed toxicities. Intern Med J. 45(7):696-701, 2015

76.Guiducci C., Vicari A. P., Sangaletti S., Trinchieri G., Colombo M. P. Redirecting in vivo elicited tumor infiltrating macrophages and dendritic cells towards tumor rejection. Cancer Res. 65, 3437-3446, 2005

77. Netea MG, Joosten LA, Latz E, Mills KH, Natoli G, Stunnenberg HG, O'Neill LA, Xavier RJ. Trained immunity: A program of innate immune memory in health and disease. Science. 352(6284):aaf1098, 2016

78.Stewart CA, Metheny H, Iida N, Smith L, Hanson M, Steinhagen F, Leighty RM, Roers A, Karp CL, Müller W, Trinchieri G. Interferon-dependent IL-10 production by Tregs limits tumor Th17 inflammation. J Clin Invest. 123(11):4859-74, 2013

79.Wallace $\mathrm{BD}$, Roberts $\mathrm{AB}$, Pollet $\mathrm{RM}$, Ingle JD, Biernat KA, Pellock SJ, Venkatesh MK, Guthrie L, O'Neal SK, Robinson SJ, Dollinger M, Figueroa E, McShane SR, Cohen RD, Jin J, Frye SV, Zamboni WC, Pepe-Ranney C, Mani S, Kelly L, Redinbo MR. Structure and Inhibition of Microbiome $\beta$-Glucuronidases Essential to the Alleviation of CancerDrug Toxicity. Chem Biol. 22(9):1238-49, 2015

80.Routy B., Le Chatelier E., Derosa L., Duong C. P. M., Alou M. T., Daillère R., Fluckiger A., Messaoudene M., Rauber C., Roberti M.P., Fidelle M., Flament C., Poirier-Colame V., Opolon P., Klein C., Iribarren K., Mondragón L., Jacquelot N., Qu B., Ferrere G., Clémenson C., Mezquita L., Masip J.R., Naltet C., Brosseau S., Kaderbhai C., Richard C., Rizvi H., Levenez F., Galleron N., Quinquis B., Pons N., Ryffel B., Minard-Colin V., Gonin P., Soria J-C, Deutsch E.,Loriot Y., Ghiringhelli F., Zalcman G., Goldwasser F., Escudier B., Hellmann M.D., Eggermont A., Raoult D., Albiges L., Kroemer G., Zitvogel L. Gut microbiome influences efficacy of 
PD-1-based immunotherapy against epithelial tumors. Science 359, 91-97, 2018

81.Spencer, C. N., Gopalakrishnan, V., McQuade, J., Andrews, M. C., Helmink, B., Khan, M. W., ... \& Wargo, J. A. (2019). The gut microbiome (GM) and immunotherapy response are influenced by host lifestyle factors.

82.Guo, M., Liu, T., Li, P., Wang, T., Zeng, C., Yang, M., ... \& Zhang, R. (2019). Association between metabolic syndrome and breast cancer risk: an updated meta-analysis of follow-up studies. Frontiers in Oncology, 9.

83.Dibaba, D. T., Ogunsina, K., Braithwaite, D., \& Akinyemiju, T. (2019). Metabolic syndrome and risk of breast cancer mortality by menopause, obesity, and subtype. Breast cancer research and treatment, 174(1), 209-218.

84. Vijay-Kumar, M., Aitken, J. D., Carvalho, F. A., Cullender, T. C., Mwangi, S., Srinivasan, S., ... \& Gewirtz, A. T. (2010). Metabolic syndrome and altered gut microbiota in mice lacking Toll-like receptor 5. Science, 328(5975), 228-231.

85.Santos-Marcos, J. A., Perez-Jimenez, F., \& Camargo, A. (2019). The role of diet and intestinal microbiota in the development of metabolic syndrome. The Journal of nutritional biochemistry, 70, 1-27.

86.Udayappan, S. D., Kovatcheva-Datchary, P., Bakker, G. J., Havik, S. R., Herrema, H., Cani, P. D., ... \& Nieuwdorp, M. (2017). Intestinal Ralstonia pickettii augments glucose intolerance in obesity. PLoS One, 12(11), e0181693.

87.Bhatt, A. P., Redinbo, M. R., \& Bultman, S. J. (2017). The role of the microbiome in cancer development and therapy. CA: a cancer journal for clinicians, 67(4), 326-344.

88. Pevsner-Fischer, M., Tuganbaev, T., Meijer, M., Zhang, S. H., Zeng, Z. R., Chen, M. H., \& Elinav, E. (2016). Role of the microbiome in nongastrointestinal cancers. World journal of clinical oncology, 7(2), 200.

89.Rao, V. P., Poutahidis, T., Ge, Z., Nambiar, P. R., Boussahmain, C., Wang, Y. Y., ... \& Erdman, S. E. (2006). Innate immune inflammatory response against enteric bacteria Helicobacter hepaticus induces mammary adenocarcinoma in mice. Cancer Research, 66(15), 7395-7400.

90.Frugé, A. D., Van der Pol, W., Rogers, L. Q., Morrow, C. D., Tsuruta, Y., \& Demark-Wahnefried, W. (2020). Fecal Akkermansia muciniphila is associated with body composition and microbiota diversity in overweight and obese women with breast cancer participating in a presurgical weight loss trial. Journal of the Academy of Nutrition and Dietetics, 120(4), 650659. 
91.Sokol, H., Pigneur, B., Watterlot, L., Lakhdari, O., Bermúdez-Humarán, L. G., Gratadoux, J. J., ... \& Langella, P. (2008). Faecalibacterium prausnitzii is an anti-inflammatory commensal bacterium identified by gut microbiota analysis of Crohn disease patients. Proceedings of the National Academy of Sciences, 105(43), 16731-16736.

92.Sivan, A., Corrales, L., Hubert, N., Williams, J. B., Aquino-Michaels, K., Earley, Z. M., ... \& Gajewski, T. F. (2015). Commensal Bifidobacterium promotes antitumor immunity and facilitates anti-PD-L1 efficacy. Science, 350(6264), 1084-1089.

93.Koeth, R. A., Wang, Z., Levison, B. S., Buffa, J. A., Org, E., Sheehy, B. T., ... \& Hazen, S. L. (2013). Intestinal microbiota metabolism of L-carnitine, a nutrient in red meat, promotes atherosclerosis. Nature medicine, 19(5), 576585 .

94.Wang, Z., Klipfell, E., Bennett, B. J., Koeth, R., Levison, B. S., DuGar, B., ... \& Hazen, S. L. (2011). Gut flora metabolism of phosphatidylcholine promotes cardiovascular disease. Nature, 472(7341), 57-63.

95.Tang, W. W., Wang, Z., Levison, B. S., Koeth, R. A., Britt, E. B., Fu, X., ... \& Hazen, S. L. (2013). Intestinal microbial metabolism of phosphatidylcholine and cardiovascular risk. New England Journal of Medicine, 368(17), 1575-1584.

96.Chan, C. W. H., Law, B. M. H., Waye, M. M. Y., Chan, J. Y. W., So, W. K. W., \& Chow, K. M. (2019). Trimethylamine-N-oxide as One Hypothetical Link for the Relationship between Intestinal Microbiota and Cancer-Where We Are and Where Shall We Go?. Journal of Cancer, 10(23), 5874.

97.Sjöström L, et al. Bariatric surgery and long-term cardiovascular events. J Am Med Assoc. 307:56-65, 2012

98.Sjöström L, et al. Effects of bariatric surgery on mortality in Swedish obese subjects. N Engl J Med. 357:741-752, 2007

99. Ridaura VK, et al. Gut microbiota from twins discordant for obesity modulate metabolism in mice. Science. 341:1241214, 2013

100. Tremaroli V, et al. Roux-en-Y gastric bypass and vertical banded gastroplasty induce long-term changes on the human gut microbiome contributing to fat mass regulation. Cell Metab. 22:228-238; 2015

101. Kovács, T., Mikó, E., Vida, A., Sebő, É., Toth, J., Csonka, T., ... \& Bai, P. (2019). Cadaverine, a metabolite of the microbiome, reduces breast cancer aggressiveness through trace amino acid receptors. Scientific reports, 9(1), 1-14. 
102. Turnbaugh PJ, et al. An obesity-associated gut microbiome with increased capacity for energy harvest. Nature. 444:1027-1031, 2006

103. Cho C., From J. Y. inflammation to cancer: advances in diagnosis and therapy for gastrointestinal and hepatological diseases. World Scientific, Singapore, 2012

104. Schwiertz A, et al. Microbiota and SCFA in lean and overweight healthy subjects. Obesity. 18:190-195, 2010

105. Meyer TW, Hostetter TH. Uremic solutes from colon microbes. Kidney Int. 81:949-954, 2012

106. Salimi, V., Shahsavari, Z., Safizadeh, B., Hosseini, A., Khademian, N., \& Tavakoli-Yaraki, M. (2017). Sodium butyrate promotes apoptosis in breast cancer cells through reactive oxygen species (ROS) formation and mitochondrial impairment. Lipids in health and disease, 16(1), 1-11.

107. Thirunavukkarasan, M., Wang, C., Rao, A., Hind, T., Teo, Y. R., Siddiquee, A. A. M., ... \& Herr, D. R. (2017). Short-chain fatty acid receptors inhibit invasive phenotypes in breast cancer cells. PloS one, 12(10), e0186334.

108. Thomas C, Pellicciari R, Pruzanski M, Auwerx J, Schoonjans K. Targeting bile-acid signalling for metabolic diseases. Nature Rev Drug Discov. 7:678-693, 2008

109. Kawamata Y, et al. A G protein-coupled receptor responsive to bile acids. J Biol Chem. 278:9435-9440, 2003

110. Sayin SI, et al. Gut microbiota regulates bile acid metabolism by reducing the levels of taurobeta-muricholic acid, a naturally occurring FXR Antagonist. Cell Metab. 17:225-235, 2013

111. Li, Z., Gao, L., Tang, H., Yin, Y., Xiang, X., Li, Y., ... \& Zhang, W. (2013). Peripheral effects of nesfatin-1 on glucose homeostasis. PloS one, 8(8), e71513.

112. Jiang, W., Wu, N., Wang, X., Chi, Y., Zhang, Y., Qiu, X., ... \& Liu, Y. (2015). Dysbiosis gut microbiota associated with inflammation and impaired mucosal immune function in intestine of humans with non-alcoholic fatty liver disease. Scientific reports, 5, 8096.

113. Parsfus A, et al. Microbiota-induced obesity requires farnesoid X receptor. Gut. 2016

114. Bruno, E., Oliverio, A., Paradiso, A. V., Daniele, A., Tommasi, S., Tufaro, A., ... \& Pasanisi, P. (2020). A Mediterranean Dietary Intervention in Female Carriers of BRCA Mutations: Results from an Italian Prospective Randomized Controlled Trial. Cancers, 12(12), 3732. 
115. Estrogen-gut microbiome axis: Physiological and clinical implications, Baker JM, Al-Nakkash L, Herbst-Kralovetz MM, Maturitas. 2017 Sep; 103:45-53.

116. The Intestinal Microbiome and Estrogen Receptor-Positive Female Breast Cancer., Kwa M, Plottel CS, Blaser MJ, Adams S., J Natl Cancer Inst. 2016 Apr 22;108(8)

117. Cavuoto P., Fenech M.F. A review of methionine dependency and the role of methionine restriction in cancer growth control and life-span extension. Cancer Treat. Rev. 38:726-736, 2012

118. Hoffman R.M. Development of recombinant methioninase to target the general cancer-specific metabolic defect of methionine dependence: A 40year odyssey. Expert Opin. Biol. Ther. 15:21-31, 2015.

119. Arrieta, M. C., Stiemsma, L. T., Amenyogbe, N., Brown, E. M., \& Finlay, B. (2014). The intestinal microbiome in early life: health and disease. Frontiers in immunology, 5, 427.

120. Selber-Hnatiw, S., Rukundo, B., Ahmadi, M., Akoubi, H., Al-Bizri, H., Aliu, A. F., ... \& Gamberi, C. (2017). Human gut microbiota: toward an ecology of disease. Frontiers in microbiology, 8, 1265.

121. Flores, R., Shi, J., Gail, M. H., Gajer, P., Ravel, J., \& Goedert, J. J. (2012). Assessment of the human faecal microbiota: II. Reproducibility and associations of $16 \mathrm{~S}$ rRNA pyrosequences. European journal of clinical investigation, 42(8), 855-863.

122. Adlercreutz, H., Martin, F., Pulkkinen, M., Dencker, H., Rimer, U., Sjoberg, N. O., \& Tikkanen, M. J. (1976). Intestinal metabolism of estrogens. The Journal of Clinical Endocrinology \& Metabolism, 43(3), 497505 .

123. Fuhrman, B. J., Feigelson, H. S., Flores, R., Gail, M. H., Xu, X., Ravel, J., \& Goedert, J. J. (2014). Associations of the fecal microbiome with urinary estrogens and estrogen metabolites in postmenopausal women. The Journal of Clinical Endocrinology \& Metabolism, 99(12), 4632-4640.

124. Yaghjyan, L., \& Colditz, G. A. (2011). Estrogens in the breast tissue: a systematic review. Cancer Causes \& Control, 22(4), 529-540.

125. Selber-Hnatiw S., Rukundo B., Ahmadi M., Akoubi H., Al-Bizri H., Aliu A.F., Ambeaghen T.U., Avetisyan L., Bahar I., Baird A., et al. Human Gut Microbiota: Toward an Ecology of Disease. Front. Microbiol. 8:1265, 2017

126. Chan A.A., Bashir M., Rivas M.N., Duvall K., Sieling P.A., Pieber T.R., Vaishampayan P.A., Love S.M., Lee D.J. Characterization of the 
microbiome of nipple aspirate fluid of breast cancer survivors. Sci. Rep. 6:28061, 2016

127. To S.Q., Knower K.C., Cheung V., Simpson E.R., Clyne C.D. Transcriptional control of local estrogen formation by aromatase in the breast. J. Steroid Biochem. Mol. Biol. 145:179-186; 2015

128. Goldin, B. R., Adlercreutz, H., Gorbach, S. L., Warram, J. H., Dwyer, J. T., Swenson, L., \& Woods, M. N. (1982). Estrogen excretion patterns and plasma levels in vegetarian and omnivorous women. New England Journal of Medicine, 307(25), 1542-1547.

129. Gorbach, S. L., \& Goldin, B. R. (1987). Diet and the excretion and enterohepatic cycling of estrogens. Preventive medicine, 16(4), 525-531.

130. Adlercreutz H. Western diet and Western diseases: Some hormonal and biochemical mechanisms and associations. Scand. J. Clin. Lab. Investig. Suppl 201:3-23, 1990

131. Saarinen, N. M., Wärri, A., Airio, M., Smeds, A., \& Mäkelä, S. (2007). Role of dietary lignans in the reduction of breast cancer risk. Molecular nutrition \& food research, 51(7), 857-866.

132. Eslami-S, Z., Majidzadeh-A, K., Halvaei, S., Babapirali, F., \& Esmaeili, R. (2020). Microbiome and Breast Cancer: New Role for an Ancient Population. Frontiers in Oncology, 10, 120.

133. McCann, S. E., Thompson, L. U., Nie, J., Dorn, J., Trevisan, M., Shields, P. G., ... \& Freudenheim, J. L. (2010). Dietary lignan intakes in relation to survival among women with breast cancer: the Western New York Exposures and Breast Cancer (WEB) Study. Breast cancer research and treatment, 122(1), 229-235.

134. Org, E., Mehrabian, M., Parks, B. W., Shipkova, P., Liu, X., Drake, T. A., \& Lusis, A. J. (2016). Sex differences and hormonal effects on gut microbiota composition in mice. Gut microbes, 7(4), 313-322.

135. DeLuca J.A., Allred K.F., Menon R., Riordan R., Weeks B.R., Jayaraman A., Allred C.D. Bisphenol-A alters microbiota metabolites derived from aromatic amino acids and worsens disease activity during colitis. Exp. Biol. Med. 243:864-875, 2018

136. Velmurugan, G., Ramprasath, T., Gilles, M., Swaminathan, K., \& Ramasamy, S. (2017). Gut microbiota, endocrine-disrupting chemicals, and the diabetes epidemic. Trends in Endocrinology \& Metabolism, 28(8), 612625 .

137. Valles-Colomer M, Falony G, Drazi Y, Tigchelaar, Wang J, Tito R Y, Schiweck C, Kurilshikov A, Joossens M, Wijmenga, Claes S, Van 
Oudenhove L, Zhernakova A, Vieira-Silva S, Raes J. The neuroactive potential oh the human gut microbiota in quality of life and depression, Nature Microbiology, 2019

138. Jean, C. Y., \& Syrjala, K. L. (2017). Anxiety and depression in cancer survivors. Medical Clinics, 101(6), 1099-1113.

139. Zhu L, Huang D, Shi L, Liang L, Xu T, Chang M, Chen W, Wu D, Zhang F, Fang X. Intestinal symptoms and psychological factors jointly affect quality of life of patients with irritable bowel syndrome with diarrhea. Health Qual Life Outcomes. 13:49; 2015

140. Liu S, Ren J, Hong Z, Li X, Yao M, Yan D, Ren H, Wu X, Wang G, $\mathrm{Gu} \mathrm{G}$, et al. An evil backstage manipulator: psychological factors correlated with health-related quality of life in Chinese patients with Crohn's disease. ScientificWorldJournal. 464698, 2013

141. De Palma G, Collins SM, Bercik P. The microbiota-gut-brain axis in functional gastrointestinal disorders. Gut Microbes. 5:419-429; 2014

142. Pritchard Rajpoot M, Sharma AK, Sharma A, Gupta GK. Understanding the microbiome: emerging biomarkers for exploiting the microbiota for personalized medicine against cancer. Semin Cancer Biol 2018

143. Selkrig J, Wong P, Zhang X, Pettersson S. Metabolic tinkering by the gut microbiome: Implications for brain development and function. Gut Microbes. 5:369-380, 2014

144. Holzer P, Farzi A. Neuropeptides and the microbiota-gut-brain axis. Adv Exp Med Biol. 817:195-219, 2014

145. Galley JD, Nelson MC, Yu Z, Dowd SE, Walter J, Kumar PS, Lyte M, Bailey MT. Exposure to a social stressor disrupts the community structure of the colonic mucosa-associated microbiota. BMC Microbiol. 14:189, 2014

146. Jiang, H., Ling, Z., Zhang, Y., Mao, H., Ma, Z., Yin, Y., ... \& Ruan, B. (2015). Altered fecal microbiota composition in patients with major depressive disorder. Brain, behavior, and immunity, 48, 186-194.

147. Kelly, J. R., Kennedy, P. J., Cryan, J. F., Dinan, T. G., Clarke, G., \& Hyland, N. P. (2015). Breaking down the barriers: the gut microbiome, intestinal permeability and stress-related psychiatric disorders. Frontiers in cellular neuroscience, $9,392$.

148. Kang, S. S., Jeraldo, P. R., Kurti, A., Miller, M. E. B., Cook, M. D., Whitlock, K., ... \& Fryer, J. D. (2014). Diet and exercise orthogonally alter the gut microbiome and reveal independent associations with anxiety and cognition. Molecular neurodegeneration, 9(1), 1-12. 
149. Ehlert U, Nater UM, Böhmelt A. High and low unstimulated salivary cortisol levels correspond to different symptoms of functional gastrointestinal disorders. J Psychosom Res. 2005;59:7-10, 2005

150. Drossman DA. Functional Gastrointestinal Disorders: History, Pathophysiology, Clinical Features and Rome IV. Gastroenterology. 2016

151. Cani PD, Bibiloni R, Knauf C, Waget A, Neyrinck AM, Delzenne NM, Burcelin R. Changes in gut microbiota control metabolic endotoxemiainduced inflammation in high-fat diet-induced obesity and diabetes in mice. Diabetes. 57:1470-1481, 2008

152. de La Serre CB, Ellis CL, Lee J, Hartman AL, Rutledge JC, Raybould HE. Propensity to high-fat diet-induced obesity in rats is associated with changes in the gut microbiota and gut inflammation. Am J Physiol Gastrointest Liver Physiol. 299:G440-G448, 2010

153. Abraham $\mathrm{C}$, Medzhitov R. Interactions between the host innate immune system and microbes in inflammatory bowel disease. Gastroenterology. 140:1729-1737, 2011

154. Valles-Colomer M, Falony G, Drazi Y, Tigchelaar, Wang J, Tito R Y, Schiweck C, Kurilshikov A, Joossens M, Wijmenga, Claes S, Van Oudenhove L, Zhernakova A, Vieira-Silva S, Raes J. The neuroactive potential oh the human gut microbiota in quality of life and depression, Nature Microbiology, 2019

155. Duboc H, Rainteau D, Rajca S, et al. Increase in fecal primary bile acids and dysbiosis in patients with diarrhea-predominant irritable bowel syndrome. Neurogastroenterol Motil 24:513-520, e246-7, 2012

156. Tana C, Umesaki Y, Imaoka A, Handa T, Kanazawa M, Fukudo S. Altered profiles of intestinal microbiota and organic acids may be the origin of symptoms in irritable bowel syndrome. Neurogastroenterol Motil 22:512-519, 2010

157. Ahmed I, Greenwood R, de Costello BL, Ratcliffe NM, Probert CS. An investigation of fecal volatile organic metabolites in irritable bowel syndrome. PLoS ONE 8:e58204, 2013

158. Annahazi A, Gecse K, Dabek M, et al. Fecal proteases from diarrheic-IBS and ulcerative colitis patients exert opposite effect on visceral sensitivity in mice. Pain ;144:209-217, 2009

159. Shankar V, Homer D, Rigsbee L, et al. The networks of human gut microbe-metabolite associations are different between health and irritable bowel syndrome. ISME J 9:1899-1903, 2015 
160. Ponnusamy K, Choi JN, Kim J, Lee SY, Lee CH. Microbial community and metabolomic comparison of irritable bowel syndrome faeces. J Med Microbiol 60(Pt 6):817-827, 2011

161. Cenac N, Bautzova T, Le FP, et al. Quantification and potential functions of endogenous agonists of transient receptor potential channels in patients with irritable bowel syndrome. Gastroenterology;149:433-444, e7, 2015

162. Treem WR, Ahsan N, Kastoff G, Hyams JS. Fecal short-chain fatty acids in patients with diarrhea-predominant irritable bowel syndrome: in vitro studies of carbohydrate fermentation. J Pediatr Gastroenterol Nutr 23:280-286, 1996

163. Cao DY, Bai G, Ji Y, Traub RJ. Epigenetic upregulation of metabotropic glutamate receptor 2 in the spinal cord attenuates oestrogen-induced visceral hypersensitivity. Gut ;64:1913-1920, 2015

164. Moloney RD, Stilling RM, Dinan TG, Cryan JF. Early-life stress-induced visceral hypersensitivity and anxiety behavior is reversed by histone deacetylase inhibition. Neurogastroenterol Motil 27:1831-1836, 2015

165. Hong S, Zheng G, Wiley JW. Epigenetic regulation of genes that modulate chronic stress-induced visceral pain in the peripheral nervous system. Gastroenterology ;148:148-157, e 7, 2015

166. Stilling RM, Dinan TG, Cryan JF. Microbial genes, brain \& behaviour - epigenetic regulation of the gut-brain axis. Genes Brain Behav 13:69-86, 2014

167. Paulsen, J. A., Ptacek, T. S., Carter, S. J., Liu, N., Kumar, R., Hyndman, L., ... \& Rogers, L. Q. (2017). Gut microbiota composition associated with alterations in cardiorespiratory fitness and psychosocial outcomes among breast cancer survivors. Supportive Care in Cancer, 25(5), 1563-1570.

168. Rao, A. V., Bested, A. C., Beaulne, T. M., Katzman, M. A., Iorio, C., Berardi, J. M., \& Logan, A. C. (2009). A randomized, double-blind, placebocontrolled pilot study of a probiotic in emotional symptoms of chronic fatigue syndrome. Gut pathogens, 1(1), 1-6.

169. Kamiya T, Wang L, Forsythe P, et al. Inhibitory effects of Lactobacillus reuteri on visceral pain induced by colorectal distension in Sprague-Dawley rats. Gut 55:191-196, 2006 